OPEN ACCESS

Edited by:

Brian Dixon

University of Waterloo, Canada

Reviewed by:

Zhihao Jia,

Purdue University, United States

Bengt Phung,

Lund University, Sweden

${ }^{\star}$ Correspondence: Xiangyong Yu yxyhhyxy@scau.edu.cn

Specialty section: This article was submitted to Comparative Immunology, a section of the journal Frontiers in Immunology

Received: 27 January 2021 Accepted: 04 May 2021 Published: 20 May 2021

Citation:

Yu F, Lu Y, Zhong Z, Qu B, Wang M, Yu X and Chen J (2021) Mitf Involved in Innate Immunity by

Activating Tyrosinase-Mediated Melanin Synthesis in Pteria penguin.

Front. Immunol. 12:626493. doi: 10.3389/fimmu.2021.626493

\section{Mitf Involved in Innate Immunity by Activating Tyrosinase-Mediated Melanin Synthesis in Pteria penguin}

\author{
Feifei $Y u^{1}$, Yishan $L u^{1}$, Zhiming Zhong ${ }^{1}$, Bingliang $Q u^{2}$, Meifang $W^{2}{ }^{3}{ }^{3}$ Xiangyong $Y u^{3 *}$ \\ and Jiayu Chen ${ }^{1}$ \\ 1 Fishery College, Guangdong Ocean University, Zhaniiang, China, 2 Faculty of Chemistry and Environmental Science, \\ Guangdong Ocean University, Zhanjiang, China, ${ }^{3}$ Ocean College, South China Agriculture University, Guangzhou, China
}

The microphthalmia-associated transcription factor (MITF) is an important transcription factor that plays a key role in melanogenesis, cell proliferation, survival and immune defense in vertebrate. However, its function and function mechanism in bivalve are still rarely known. In this research, first, a Mitf gene was characterized from Pteria penguin ( $P$. penguin). The PpMitf contained an open reading frame of 1,350 bp, encoding a peptide of 449 deduced amino acids with a highly conserved basic helix-loop-helixleucine zipper (bHLH-LZ) domain. The PpMITF shared 55.7\% identity with amino acid sequence of Crassostrea gigas (C. gigas). Tissue distribution analysis revealed that PpMitf was highly expressed in mantle and hemocytes, which were important tissues for color formation and innate immunity. Second, the functions of PpMitf in melanin synthesis and innate immunity were identified. The PpMitf silencing significantly decreased the tyrosinase activity and melanin content, indicating PpMitf involved in melanin synthesis of $P$. penguin. Meanwhile, the PpMitf silencing clearly down-regulated the expression of PpBcl2 (B cell lymphoma/leukemia-2 gene) and antibacterial activity of hemolymph supernatant, indicating that PpMitf involved in innate immunity of $P$. penguin. Third, the function mechanism of PpMitf in immunity was analyzed. The promoter sequence analysis of tyrosinase (Tyr) revealed two highly conserved E-box elements, which were specifically recognized by HLH-LZ of MITF. The luciferase activities analysis showed that Mitf could activate the E-box in Tyr promoter through highly conserved bHLH-LZ domain, and demonstrated that PpMitf involved in melanin synthesis and innate immunity by regulating tyrosinase expression. Finally, melanin from $P$. penguin, the final production of Mitf-Tyrmelanin pathway, was confirmed to have direct antibacterial activity. The results collectively demonstrated that PpMitf played a key role in innate immunity through activating tyrosinase-mediated melanin synthesis in $P$. penguin.

Keywords: Mitf, melanin, tyrosinase, innate immunity, Pteria penguin 


\section{INTRODUCTION}

Invertebrates lack highly evolved adaptive immunity system, and completely rely on innate immunity mediated by both cellular and humoral components to protect the host from microbial challenge $(1,2)$. Most invertebrates have several innate immune responses, of which melanization is an important humoral immune response $(3,4)$. By melanization, the melanin is largely synthesized and deposited in infected site for wound healing, phagocytosis, parasite entrapment and microbe killing $(1,5)$. Although there is no typical melanization observed in bivalve, the melanin and the enzymes involved in melanin synthesis are speculated to be important for innate immunity of bivalve $(1,6)$.

The microphthalmia-associated transcription factor (MITF) is a member of microphthalmia-associated transcriptional factor (MiT) family of transcription factors $(7,8)$. MITF acts as a central transcription factor to regulate the expression of tyrosinase (Tyr), an initial and rate-limiting enzyme of melanin synthesis, and controls the melanin production $(9,10)$. MITF also participates in immune defense by regulating lots of target genes in innate immune signaling pathway, such as tyrosinase, pthnoloxidase $(P O)$, cathepsin K (CTSK) and B cell lymphoma/ leukemia-2 (BCL2) $(7,11,12)$. Although Mitf genes have been widely reported in vertebrates, the reports in bivalve are quite meager, only two Mitf genes have been identified from Patinopecten yessoensis and Meretrix petechialis so far $(13,14)$. It is not known whether Mitf performs a similar function in melanin synthesis and innate immunity of bivalve.

The winged pearl oyster Pteria penguin ( $P$. penguin) is an important commercial bivalve cultivated in South Sea, and is used to produce high-quality sea pearls (15). P. penguin has pure black shell, suggesting the existence of abundant melanin. Our previous researches have confirmed that melanin determines the color formation of nacre of $P$. penguin $(16,17)$. It is worth studying whether melanin involves in innate immunity, and how melanin-synthesis related genes regulate the innate immune response of bivalve.

In this research, we characterized the new Mitf gene from $P$. penguin, and confirmed it played a crucial role in both melanin synthesis and innate immunity. Moreover, mechanism studies showed that PpMitf was involved in innate immunity by activating tyrosinase and motivating the biosynthesis of melanin. Mitf-Tyr-melanin pathway is an essential pathway in innate immunity of $P$. penguin

\section{MATERIALS AND METHODS}

\section{Experimental Animals and Arbutin Treatment}

The $P$. penguin used in this research were cultivated in Weizhou Island in Beihai, Guangxi Province, China. Their shell length is $14 \pm 1 \mathrm{~cm}$, weighing $400 \pm 50 \mathrm{~g}$. They were held in circulating seawater at $25 \pm 0.5^{\circ} \mathrm{C}$ for 5 days in lab prior to experiments. If necessary, the experimental individuals were immersed in
$10 \mathrm{mM}$ arbutin diluted with seawater for 7 days to inhibit tyrosinase activity.

\section{RNA Interference Experiment and Samples Collection}

RNA interference was performed to identify the function of PpMitf gene. The PpMitf-siRNA1 was synthesized to silence the N-terminal conserved region, and PpMitf-siRNA2 was synthesized to silence the highly conserved HLH-LZ domain. The GFP-siRNA was synthesized from pEGFP-N3 plasmid as a negative control (NC) (primers as Table 1). In blank group, the experimental animals were cultivated with the recirculating seawater without any treatment. Double-stranded RNA (dsRNA) was synthesized with T7 High Efficiency Transcription Kit (TransGen, China) and purified with EasyPure RNA Purification Kit (TransGen, China). $100 \mu \mathrm{l}$ of 1 $\mu \mathrm{g} / \mu \mathrm{l}$ dsRNA were gently injected into adductor muscle of experimental individuals, and were injected again at the 5th day with the same dose to enhance the silencing effect. At the 8th day, the mantle was collected for RNA extraction, tyrosinase activity assay and melanin analysis. The hemolymph was collected from adductor muscle and immediately centrifuged at $800 \mathrm{~g}, 4^{\circ} \mathrm{C}$ for $10 \mathrm{~min}$ to separate the hemocytes and supernatant. The hemocytes were harvested for tissue distribution analysis, and the supernatant was filter-sterilized $(0.22 \mu \mathrm{m})$ for antibacterial activity. Each of the experimental groups contained five individuals.

\section{RNA Isolation and cDNA Synthesis}

Total RNA were isolated from about $2 \mathrm{~g}$ of mantle, gill, adductor muscle, digestive diverticulum, foot, gonad and hemocytes of $P$. penguin using RNeasyMini Kit (Qiagen, USA). The single strand cDNA was synthesized from total RNA using a Superscript II polymerase kit (TransGen, China) and used as templates of RealTime PCR. The random primers was employed for cDNA synthesis.

\section{The cDNA Cloning and Sequence Analysis}

The full-length cDNA of Mitf was obtained with SMART RACE cDNA Amplification Kit (Clontech, USA) and Advantage 2 cDNA Polymerase Mix (Clontech, USA). The specific primers (PpMitf-outer-F and PpMitf-outer-R) were designed based on the partial sequence from the transcriptome, and were used to amplify the 3' and 5' sequences. The nested-PCR was performed to enrich the specific DNA band using PpMitf-inner-F and PpMitf-inner-R. The nested-PCR program was conducted as follows: $94^{\circ} \mathrm{C}$ for $4 \mathrm{~min}, 35$ cycles $\left(94^{\circ} \mathrm{C}\right.$ for $30 \mathrm{~s}, 57^{\circ} \mathrm{C}$ for $30 \mathrm{~s}$ and $72^{\circ} \mathrm{C}$ for $1 \mathrm{~min} 20 \mathrm{~s}$ in each cycle) and $72^{\circ} \mathrm{C}$ for $10 \mathrm{~min}$. The test-PCR was employed to certify the nucleotide sequence using PpMitf-test-F and PpMitf-test-R. All primers were showed in Table 1.

The Mitf cDNA was analyzed using the BLAST program, and the open reading fragment (ORF) was identified using ORF Finder. The signal peptide was predicted by SignalP. Multiple sequences were aligned using Clustal $\mathrm{W}$, and phylogenetic tree was constructed using MEGA 6 . The protein molecular weight 
TABLE 1 | Primers used in the study.

\begin{tabular}{|c|c|c|}
\hline Primer & Sequence $\left(5^{\prime}-3^{\prime}\right)$ & Application \\
\hline PpMitf-outer-F & GACCCAGATAGTCCCCTGTCAGCAGG & 3'RACE \\
\hline PpMitf-inner-F & AGCTTGATAGAGCCTACCCTTAATCAG & nest-3'RACE \\
\hline PpMitf-outer-R & TTGAGGTTGATGTTGAGGTTGAGACTG & 5'RACE \\
\hline PpMitf-inner-R & AGACCATGTGCTICATTACCAACTCC & nest-5'RACE \\
\hline UPM (Universal Primer) & $\begin{array}{l}\text { TAATACGACTCACTATAGGGCAAGCAGTGGTATC } \\
\text { AACGCAGAGT }\end{array}$ & RACE universal primer \\
\hline NUP (Nested Universal Primer) & AAGCAGTGGTATCAACGCAGAGT & Nest-RACE universal primer \\
\hline PpMitf-test-F & ATGCAGGACTCTGGAATCGAATATG & cDNA test \\
\hline PpMitf-test-R & TCACAGCAAATCGTTCGATTCGGA & cDNA test \\
\hline PpMitf-siRNA1-F & GCGTAATACGACTCACTATAGGGGACCATCAAAACCGAGACACAAGCA & RNAi \\
\hline PpMitf-siRNA1-R & GCGTAATACGACTCACTATAGGGAAATTAGCTGGACAGGAAGAGGAGC & RNAi \\
\hline PpMitf-siRNA2-F & GCGTAATACGACTCACTATAGGGGGACAGACAGAAGAAGGATAATCAC & RNAi \\
\hline PpMitf-siRNA2-R & GCGTAATACGACTCACTATAGGGAGTTCATCTCGCTIGAGGTTGATG & RNAi \\
\hline PpMitf-pcDNA3.1-F & GTAGCTAGCATGCAGGACTCTGGAATCGA & Luciferase activity analysis \\
\hline PpMitf-pcDNA3.1-R & GCTCTAGATCACAGCAAATCGTTCGATT & Luciferase activity analysis \\
\hline GFP-siRNA-F & GATCACTAATACGACTCACTATAGGGATGGTGAGCAAGGGCGAGGA & RNAi \\
\hline GFP-siRNA-R & $\begin{array}{l}\text { GATCACTAATACGACTCACTATAGGGTTACTTGTAC } \\
\text { AGCTCGTCCA }\end{array}$ & RNAi \\
\hline Tyr-SP1 & CAGTATAGTTAAGTCTGTACTGC & Genomic Walking \\
\hline Tyr-SP2 & GTAGATATITGCAGGTATGAAAG & Genomic Walking \\
\hline Tyr-SP3 & GATCTGTGAGAGATATAAACTTC & Genomic Walking \\
\hline Tyr-pro-F & GAAGAGCTCAAGACAGAATG & Promoter verification \\
\hline Tyr-pro-R & CAGTATAGTTAAGTCTGTACTGC & Promoter verification \\
\hline Tyr-pro-luc-F & CTTGCTAGCACTAATGGGACTCTAGCAGG & Luciferase activity analysis \\
\hline Tyr-pro-luc-R & CGCAAGCTTAATCAAATTCCTAAAGCACT & Luciferase activity analysis \\
\hline PpTyr-qPCR-F & CTCAGGGAAGGGATCAGCTT & qRT-PCR \\
\hline PpTyr-qPCR-R & AGACCCTCTGCCATTACCAA & qRT-PCR \\
\hline PpMitf-qPCR-F & TGTTACCTAAATCTGTTGATCCAG & qRT-PCR \\
\hline PpMitf-qPCR-R & AAATTAGCTGGACAGGAAGAGGAG & qRT-PCR \\
\hline PpBc/2-qPCR-F & TGAGGCACAGTTCCAGGATT & qRT-PCR \\
\hline PpBcl2-qPCR-R & ACTCTCCACACACCGTACAG & qRT-PCR \\
\hline PpCdk2-qPCR-F & TGGATTTGCTCGGACACTTG & qRT-PCR \\
\hline PpCdk2-qPCR-R & TCTACTGCССTGCCATACTT & qRT-PCR \\
\hline$\beta$-actin- $F$ & CGGTACCACCATGTTCTCAG & qRT-PCR \\
\hline$\beta$-actin-R & GACCGGATTCATCGTATTCC & qRT-PCR \\
\hline
\end{tabular}

and theoretical $\mathrm{pI}$ were analyzed by programs online (http://web. expasy.org/cgibin/protparam/protparam).

\section{Quantitative Real-Time PCR (qRT-PCR) Analysis}

The Real-Time PCR was performed by the Applied Biosystems 7500/7500 Fast Real-time System (ABI, USA) following the manufacturer's protocol of DyNAmo Flash SYBR Green qPCR Kit (Thermo scientific, USA). The reaction was run in a $10 \mu \mathrm{l}$ volume containing $20 \mathrm{ng}$ of cDNA, $0.3 \mu \mathrm{M}$ of each primer and $5 \mu \mathrm{l} \mathrm{SYBR}$ green Master Mix. The PCR parameters were $95^{\circ} \mathrm{C}$ for $2 \mathrm{~min}$, followed by 38 cycles of $95^{\circ} \mathrm{C}$ for $5 \mathrm{~s}, 58^{\circ} \mathrm{C}$ for $20 \mathrm{~s}$ and $72^{\circ} \mathrm{C}$ for $20 \mathrm{~s}$. The specific primers were listed in Table 1, and $\beta$-actin was used as internal control. The $2^{-\Delta \Delta C T}$ method was applied to calculate the relative expression levels of genes. Each reaction was repeated in triplicate.

\section{Tyrosinase Activity Assay}

Tyrosinase activity assays were performed following the previous reports with minor modification (17-19). $1 \mathrm{~g}$ mantle tissue was homogenized in $3 \mathrm{ml}$ of $0.1 \mathrm{~mol} / \mathrm{L}$ Phosphate Buffered Saline (PBS, $\mathrm{pH}$ 6.8), and was centrifuged at $12,000 \mathrm{~g}$ for $10 \mathrm{~min}$ to obtain the supernatant (about $1 \mathrm{ml}$ ). Then, $0.5 \mathrm{ml}$ of $5 \mathrm{mmol} / \mathrm{L} 3$, 4-dihydroxyphenylalanine (L-DOPA) was mixed with all the supernatant, and incubated at $37^{\circ} \mathrm{C}$ for $30 \mathrm{~min}$. The absorbance of the mixture was recorded at $475 \mathrm{~nm}$. The tryosinase activity was defined as increased or decreased absorbance in $30 \mathrm{~min}$ at $475 \mathrm{~nm}$.

\section{Isolation and Oxidation of Total Melanin}

The melanin was isolated from mantle of $P$. penguin and oxidized as follows (15). $1 \mathrm{~g}$ mantle sample was finely homogenized on ice, mixed with $15 \mathrm{ml}$ PBS (pH 7.4) with $2 \%$ $(\mathrm{m} / \mathrm{V})$ papain (J\&K, China), and incubated at $55^{\circ} \mathrm{C}$ for $20 \mathrm{~h}$. The precipitate was obtained by centrifuging at $12,000 \mathrm{~g}$ for $10 \mathrm{~min}$, and then was successively washed with $2 \mathrm{ml}$ mineral ether, ethanol and water. After that, the obtained black precipitate was raw melanin production.

$8.6 \mathrm{ml}$ of $1 \mathrm{~mol} / \mathrm{L} \mathrm{K}_{2} \mathrm{CO}_{3}$ and $0.8 \mathrm{ml}$ of $30 \% \mathrm{H}_{2} \mathrm{O}_{2}$ were used to dissolve and oxidize the raw melanin. The mixture was heated at $100^{\circ} \mathrm{C}$ for $20 \mathrm{~min}$ and cooled down to room temperature. The residual $\mathrm{H}_{2} \mathrm{O}_{2}$ was decomposed by $0.4 \mathrm{ml}$ of $10 \% \mathrm{Na}_{2} \mathrm{SO}_{3}$, and 6 $\mathrm{mol} / \mathrm{L} \mathrm{HCl}$ was then added to adjust $\mathrm{pH}$ to 1.0 . The mixture was centrifuged at $8,000 \mathrm{~g}$ for $10 \mathrm{~min}$ to get the supernatant, which then was extracted using $70 \mathrm{ml}$ of ether and dried to crystalline residue. Finally, crystalline residues were redissolved in mobile 
phase or water, and were filtered through $0.45 \mu \mathrm{m}$ nylon membrane (Millipore, USA) before using.

\section{LC-MS/MS Assay of Melanin}

The liquid chromatograph-tandem mass spectrometer (LC-MS/ MS) was employed to detect the content and component of melanin $(16,20)$. The chromatographic separation was performed using an Acquity ultraperformance liquid chromatography (UPLC) system (Waters, USA) with a Waters ACQUITY UPLC HSS T3 $(2.1 \times 50 \mathrm{~mm}, 1.7 \mu \mathrm{m}$ particle size $)$. The mobile phase A was $0.1 \%$ of formic acid/deionized water $(v / v)$, and mobile phase B was $0.1 \%$ of formic acid/methanol $(v / v)$. The ratio of mobile phases A and B was 9:1 in the first $3 \mathrm{~min}$, and 1:9 in the last $3 \mathrm{~min}$. It kept $6 \mathrm{~min}$ in one cycle. Analyses were performed at $40^{\circ} \mathrm{C}$ at a flow rate of $0.3 \mathrm{ml} / \mathrm{min}$. As the MS/MS detection, a Xevo TQ triple quadrupole mass spectrometer was operated in positive electrospray ionization (ESI) mode. The Mass spectrometer parameters were as follows: The source temperature was $150^{\circ} \mathrm{C}$, and desolvation temperature was $550^{\circ} \mathrm{C}$. The cone gas flow, desolvation gas flow and collision gas flow were $50 \mathrm{~L} / \mathrm{h}$, $1.100 \mathrm{~L} / \mathrm{h}$ and $0.14 \mathrm{ml} / \mathrm{min}$ (argon), respectively. The analytes were monitored in multireaction monitoring mode (MRM).

\section{Genome Walking}

The promoter region of PpTyr was cloned using the Universal Genome Walker 2.0 Kit (Clontech, USA). The Genome Walker libraries were constructed using the genomic DNA, which was extracted from P. penguin by E.Z.N.A. Tissue DNA Kit (Omega, America). Three primers (Tyr-SP1, Tyr-SP2 and Tyr-SP3) were designed to amplify the single DNA fragments of Tyr. The PCR program was conducted as follow: $94^{\circ} \mathrm{C}$ for $1 \mathrm{~min}, 98^{\circ} \mathrm{C}$ for $1 \mathrm{~min}$, five cycles $\left(94^{\circ} \mathrm{C}\right.$ for $30 \mathrm{~s}, 62^{\circ} \mathrm{C}$ for $1 \mathrm{~min}$ and $72^{\circ} \mathrm{C}$ for $3 \mathrm{~min}$ in each cycle), 15 cycles $\left(94^{\circ} \mathrm{C}\right.$ for $30 \mathrm{~s}, 25^{\circ} \mathrm{C}$ for $3 \mathrm{~min}$, $72^{\circ} \mathrm{C}$ for $3 \mathrm{~min} ; 94^{\circ} \mathrm{C}$ for $30 \mathrm{~s}, 62^{\circ} \mathrm{C}$ for $1 \mathrm{~min}, 72^{\circ} \mathrm{C}$ for $3 \mathrm{~min}$; $94^{\circ} \mathrm{C}$ for $30 \mathrm{~s}, 44^{\circ} \mathrm{C}$ for $1 \mathrm{~min}, 72^{\circ} \mathrm{C}$ for $3 \mathrm{~min}$ ) and $72^{\circ} \mathrm{C}$ for $10 \mathrm{~min}$. Then the Tyr-pro-F and Tyr-pro-R were used to verify the amplified sequence (Table 1).

\section{Plasmids Construction}

The Mitf-pcDNA3.1 plasmid was made by inserting the Mitf ORF sequence into pcDNA 3.1 vector with NheI and XbaI. The primers PpMitf-pcDNA3.1-F and PpMitf-pcDNA3.1-R were used to amplify the Mitf ORF (Table 1). The Mitf- $\triangle$ HLHLZ sequence, which was HLHLZ-deleted-Mitf ORF sequence (deletion from 854 to 1,022 ), was synthesized and inserted into the pcDNA3.1 vector with NheI and XbaI to construct the Mitf$\triangle$ HLHLZ-pcDNA3.1 plasmid.

The Tyr promoter-driven luciferase reporter construct (Tyrpromoter-Luc) was made by inserting the whole Tyr promoter region (from $-1,943$ to -1 ) in front of the luciferase reporter gene in pGL3-Basic vector. The primers Tyr-pro-luc-F and Tyr-proluc-R were used to amplify the Tyr promoter fragment (Table 1). The Ebox-deleted-promoters were synthesized and inserted into the pGL3-Basic vector to construct the Tyr- $\triangle$ Ebox1-promoterLuc (deletion from $-1,767$ to $-1,761$ ), Tyr- $\triangle$ Ebox2-promoterLuc (deletion from $-1,613$ to $-1,607$ ) and Tyr- $\triangle$ Eboxespromoter-Luc plasmids (deletion from $-1,767$ to $-1,607$ ).
The NheI and HindIII were employed to digest the DNA fragment and pGL3-Basic vector.

\section{Luciferase Activity Assay}

To analyze the Tyr promoter activity, 293T cells were grown in DMEM medium supplemented with $10 \%$ fetal calf serum (FCS) at $37^{\circ} \mathrm{C}$ in incubator with $\mathrm{CO}_{2} .0 .4 \mu \mathrm{g}$ of Tyr-promoter-Luc vector and $0.04 \mu \mathrm{g}$ pRL-cmv vector were diluted in $50 \mu \mathrm{l}$ DMEM and mixed with $1 \mu \mathrm{l}$ of Lipofectamine 2000 (Invitrogen, USA) in $50 \mu \mathrm{l}$ DMEM. After incubation for $5 \mathrm{~min}$ at room temperature, the $100 \mu \mathrm{l}$ of mixture was transfected into cells in 24-well plate. $0.4 \mu \mathrm{g}$ of pGL3-Basic vector and $0.04 \mu \mathrm{g} \mathrm{pRL}-\mathrm{cmv}$ vector were transfected as control. After $48 \mathrm{~h}$, the cells were collected and lysed using the Dual-Luciferase Reporter Assay System (Promega, America). The fluorescence intensity was measured by Junior LB9509 Luminometer. Luciferase activities were presented by relative light units (RLU) of firefly fluorescence to Renilla fluorescence. Each independent experiment was repeated five times.

To analyze the regulation of Mitf on Tyr promoter, the transfected $293 \mathrm{~T}$ cells were cotransfected with $0.4 \mu \mathrm{g}$ MitfpcDNA3.1, $0.4 \mu \mathrm{g}$ of Tyr-promoter-Luc vector and $0.04 \mu \mathrm{g}$ pRL-cmv vector, $0.4 \mu \mathrm{g}$ pcDNA3.1 plasmid was used as control. To confirm the function of conserved HLH-LZ domain in MITF, Mitf- $\triangle$ HLHLZ-pcDNA3.1, Tyr-promoterLuc and pRL-cmv plasmids were cotransfected into 293T cells. To elaborate the role of E-box in Tyr promoter, the MitfpcDNA3.1, Tyr- $\triangle$ Ebox-promoter-Luc plasmid and pRL-cmv vector were cotransfected.

\section{Western Blot}

The equal amounts of transfected 293T cells were collected and used for proteins extraction with TRIZOL reagent (Invitrogen, USA) according to the previous report (21). The protein extracts were separated on the $12 \%$ SDS-PAGE gel and electrophoretically transferred to a PVDF membrane (Millipore, USA). The membrane was blocked with 3\% BSA (Bovine serum albumin)/ PBS (phosphate buffer saline) for whole night, and then was washed for three times by PBST, each for $10 \mathrm{~min}$. The membrane was incubated with primary antibody in 1\% BSA/ PBS for $1.5 \mathrm{~h}$, washed three times and then incubated with secondary antibody for $1 \mathrm{~h}$ at room temperature. After another three 10-min washes with PBST, the membrane was stained with NBT/BCIP staining system (Sigma-Aldrich, USA) and by detected in dark. The anti-Flag antibody (Yeasen, China) was used as primary antibody with dilution ratio of 1:1,000. The anti-actin antibody (Yeasen, China) was used as an internal control with dilution ratio of 1:4,000. The HRP-conjugated goat anti-rabbit IgG (Sigma-Aldrich, USA) was used as secondary antibody at 1:4,000.

\section{Antibacterial Activity Assay of Hemolymph Supernatant}

The antibacterial activity of the hemolymph supernatant was assayed using the method described previously $(22,23)$. The protein concentrations in haemolymph supernate from NC, siRNA1 and siRNA2 groups were adjusted to $1.0 \mathrm{mg} / \mathrm{ml}$ using Nanodrop spectrophotometers (Thermo scientific, USA). The $50 \mu \mathrm{l}$ 
of sterile hemolymph supernatant was mixed with $50 \mu \mathrm{l}$ of $E$. coli containing pMD-18T vector (TaKaRa, Japan) at a density of $1 \times 10^{6}$ colony forming units $(\mathrm{CFU}) / \mathrm{ml}$, and incubated at $37^{\circ} \mathrm{C}$ for $30 \mathrm{~min}$ with shaking. Then, $50 \mu \mathrm{l}$ of mixture was diluted with $250 \mu \mathrm{LB}$ medium, and pipetted into a sterile 96 -well plate. The plate was incubated at $37^{\circ} \mathrm{C}$ for $12 \mathrm{~h}$, and the absorbance at $600 \mathrm{~nm}$ was measured at intervals of 30min. The time when OD600 absorbance of NC group reached the maximum was recorded, and half of the time was defined as T50. The OD600 value at T50 was used to represent the anti-bacterial activity of hemolymph supernatant. Five individuals were used in each treatment group.

\section{Antibacterial Activity Assay of Melanin Oxidation Products}

The E. coli with pMD-18T vector (TaKaRa, Japan) was cultured to a density of $1 \times 10^{6} \mathrm{CFU} / \mathrm{ml}$ (24). The melanin of $1 \mathrm{~g}$ mantle from NC, siRNA1 and siRNA2 groups was extracted, oxidized, filtered and resolved in $50 \mu \mathrm{l}$ sterilized water. Then, $50 \mu \mathrm{l}$ melanin oxidation production was mixed with $150 \mu \mathrm{l}$. coli with ampicillin resistance, and shaken for $0.5 \mathrm{~h}$ at $37^{\circ} \mathrm{C}$. In melanin-addition groups, $0.1 \mathrm{~g}$ melanin (J\&K, China) was oxidized, filtered, resolved and added into the mixture. Then, $100 \mu \mathrm{l}$ mixture was evenly spread on plates with LB medium and $50 \mu \mathrm{g} / \mathrm{ml}$ ampicillin. After incubation at $37^{\circ} \mathrm{C}$ for $24 \mathrm{~h}$, the number of visible colonies was counted.

\section{Statistical Analysis}

Analysis of Variance (ANOVA) was performed to determine the significant differences in different samples ( $n=$ six replicates) by SPSS (Version 17.0, Chicago, IL, USA). Data were shown as mean \pm SD. ${ }^{*}(P<0.05)$ meant significant difference, and ${ }^{* *}$ $(P<0.01)$ meant highly significant difference.

\section{RESULTS}

\section{Cloning and Sequence Analysis of Mitf cDNA in $P$. penguin}

The complete coding sequence of Mitf in P. penguin was cloned from mantle by RACE-PCR and named as PpMitf (Genbank accession no. MN296415). The complete nucleotide sequence of PpMitf was 1,774 bp in length, containing a 1350-bp open reading frame (69-1,418), a 68-bp 5'-untranslated region (UTR) and a 356-bp 3'-UTR with a typical signal sequence (AATAA) located upstream of poly (A) tail (Figure 1). The ORF encoded 449 deduced amino acids without a signal peptide. The predicted polypeptide sequence contained a basic helix-loophelix-leucine zipper (bHLH-LZ) domain, which recognized with E-box or M-box of downstream genes. The deduced molecular mass of PpMitf protein was $50.5 \mathrm{kDa}$ with a theoretical isoelectric point (pI) of 5.34 .

\section{Multiple Sequence Alignment and Phylogenetic Analyses}

The DNAMAN6 software (Lynnon Biosoft, Canada) was used to determine the homology among Mitf gene from different species.
The PpMitf shared the highest sequence similarity (55.7\%) with Mitf gene of Crassostrea gigas, and 53.7, 51.6 and 51.3\% sequence similarity with Mitf-like genes of Crassostrea virginica, Pecten maximus and Mizuhopecten yessoensis, respectively. The amino acid sequence comparison showed a highly conserved basic HLH-LZ domain among mollusks, fish, amphibians, birds and mammals. Another relatively conserved region was in the $\mathrm{N}$ terminal, and named as $\mathrm{N}$-terminal conserved domain. (Figures 1 and $\mathbf{2 A}$ )

To understand the evolutionary relationships among PpMitf and that of other species, the phylogenetic tree was constructed using MEGA7 (Figure 2B). The PpMitf was located in one clade with Mitf protein of C. gigas and Mitf-like protein of C. virginica, indicating that they were the most closely related homologs. Moreover, seven Mitf genes of bivalves, including P. penguin, C. gigas, C. virginica, M. yessoensis, Hyriopsis cumingii, $P$. maximus and Mytilus coruscus, were contained in a close cluster. The Mitf genes of Pomacea canaliculata and Octopus vulgaris showed high homology with bivalves. On the other hand, all Mitf genes of vertebrates referred, including Danio rerio, Xenopus laevis, Gallus gallus and Mus musculus, were grouped into a big clade, and showed low homology with PpMitf gene.

\section{PpMitf Expression Profile in Different Tissues}

Using the qRT-PCR, the PpMitf mRNA levels from various tissues were investigated (Figure 3). PpMitf gene showed the highest expression levels in mantle and hemocytes, higher levels in gill and digestive diverticulum, and the lowest levels in adductor muscle, foot and gonad. Since PpMitf was mainly expressed in the mantle, which was responsible for melanin synthesis, nacre formation and innate immune response, the mantle was then used for gene expression, tyrosinase activity and melanin content analysis.

\section{PpMitf Silencing Inhibited Tyrosinase Activity}

RNA interference was conducted to examine the role of Mitf in melanin synthesis of $P$. penguin. The PpMitf-siRNA1 and PpMitf-siRNA2 were used to specifically silence the N-terminal conserved region and the HLH-LZ domain (Figure 4A). The PpMitf mRNA levels were measured by qRT-PCR after RNAi. Figure 4B showed that the PpMitf transcripts were downregulated by $42.1 \%(P<0.05)$ and $65.9 \%(P<0.01)$ in siRNA1 and siRNA2 groups compared with the negative control (NC) group, indicating RNA interference produced a good silencing effect of PpMitf mRNA.

Tyrosinase activity is regarded as a marker of melanin biosynthesis because of its role as a key rate-limiting enzyme. The tyrosinase activity was represented by change in absorbance owing to the conversion of dopaquinone to dopachrome. The tyrosinase activity was significantly decreased by $30.2 \%$ through silencing $\mathrm{N}$-terminal conserved domain (siRNA1 group) $(P<0.05)$ and by $49.6 \%$ through silencing bHLH-LZ domain (siRNA2 group) $(P<0.01)$ compared to NC group (Figure $4 B$ ). In positive control group, the experimental individuals were 


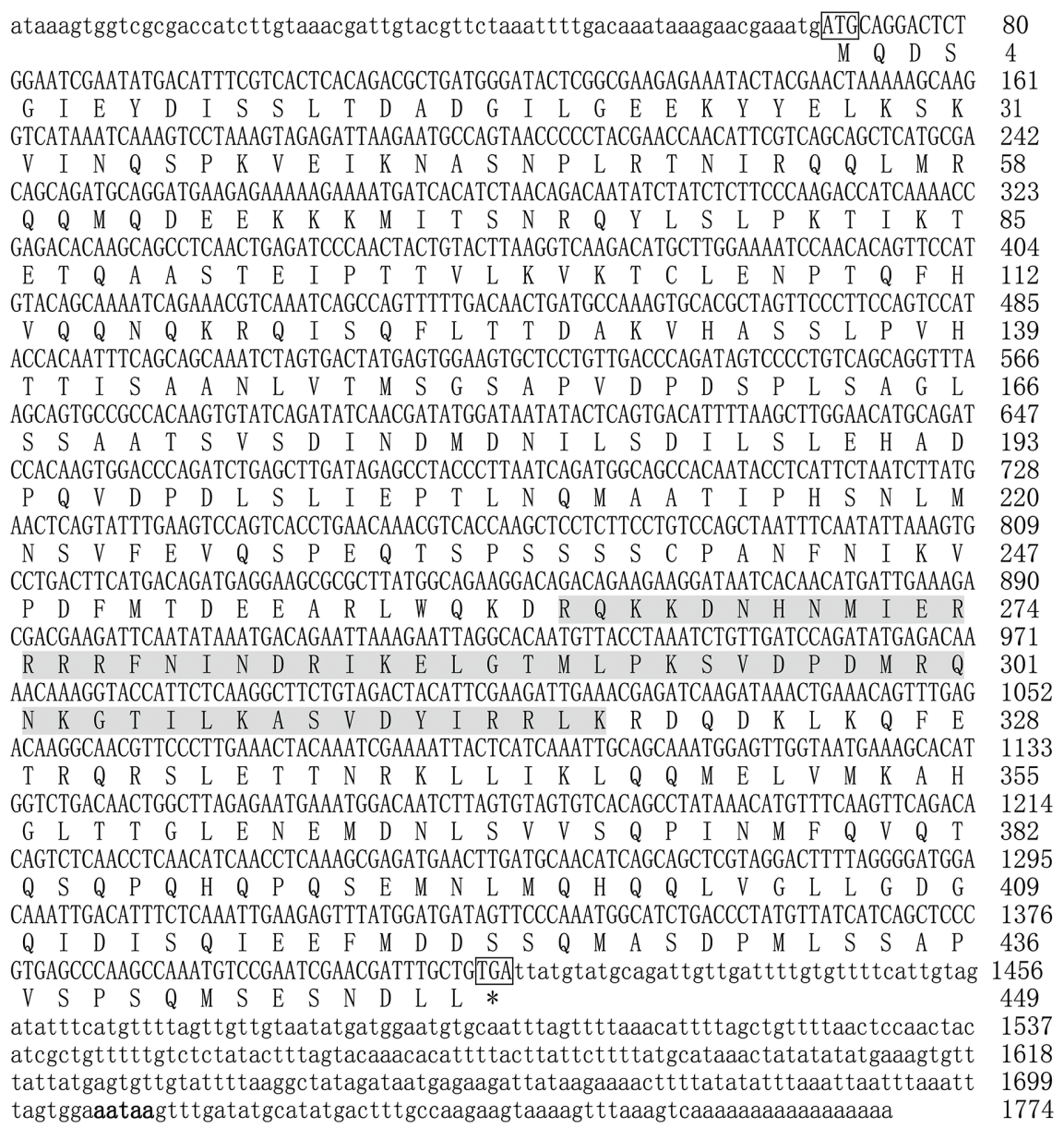

FIGURE 1 | The full-length nucleotide and deduced amino acid sequences of PpMitf. The ORF sequence was displayed in uppercase, the 5' UTR and 3' UTR sequences were displayed in lowercase. The initiation codon (ATG) and termination codon (TGA) were boxed. The putative bHLH-LZ domains were boxed in gray. The signal peptide (aataa) was marked in boldface. ${ }^{*}$ meant no amino acid was coded.

immersed in $10 \mathrm{mM}$ arbutin, a typical tyrosinase activity inhibitor, and their tyrosinase activities were analyzed. The tyrosinase activity was significantly inhibited by $68.8 \%$ after arbutin treatment compared to blank group $(P<0.01)$. This results indicated that the PpMitf silencing could inhibit tyrosinase activity in $P$. penguin.

\section{PpMitf Silencing Reduced Melanin Content}

After RNA interference, the qualitative and quantitative analysis of melanin were performed by LC-MS/MS. The mass spectrometry analysis verified that the main alkaline oxidation products of melanin from P. Penguin were pyrrole-2, 3-dicarboxylic acid (PDCA) and pyrrole-2, 3, 5-tricarboxylic acid (PTCA), with molecular weight at 156 and $199 \mathrm{~g} / \mathrm{mol}$. The quantitative analysis was measured based on the peak area of PDCA and PTCA, which appeared at 2.42 and $3.62 \mathrm{~min}$ (Figure 5A). The PDCA content was reduced by $35.9 \%$ through N-terminal conserved domain knockdown (siRNA1 group), and $48.5 \%$ through bHLH-LZ domain knockdown (siRNA2 group) $(P<0.05)$. Similarly, the PTCA content was reduced by $29.1 \%$ by siRNA1 $(P<0.05)$ and $42.8 \%$ by siRNA2 $(P<0.01)$. The total content of PDCA and PTCA was clearly decreased by $30.2 \%$ through $\mathrm{N}$-terminal conserved domain knockdown $(P<0.05)$, by $45.2 \%$ through HLH-LZ domain knockdown $(P<0.01)$, and by $65.9 \%$ through arbutin treatment $(P<0.01)$ (Figure 5B). The data indicated that PpMitf regulated melanin synthesis in $P$. penguin.

\section{Mitf Silencing Inhibited the Transcription of Tyr, Cdk2 and Bcl2 in P. penguin}

Since PpMitf silencing significantly reduced the tyrosinase activity and melanin content, we speculated that PpMitf silencing might inhibit the expression of tyrosinase gene in $P$. penguin. To prove this point, qRT-PCR was employed to detect the transcript level of PpTyr. As expected, the PpTyr mRNA was significantly down-regulated by $37.9 \%(P<0.05)$ by Mitf-siRNA1 and $61.0 \%(P<0.01)$ by Mitf-siRNA2 (Figure 6). This suggested 


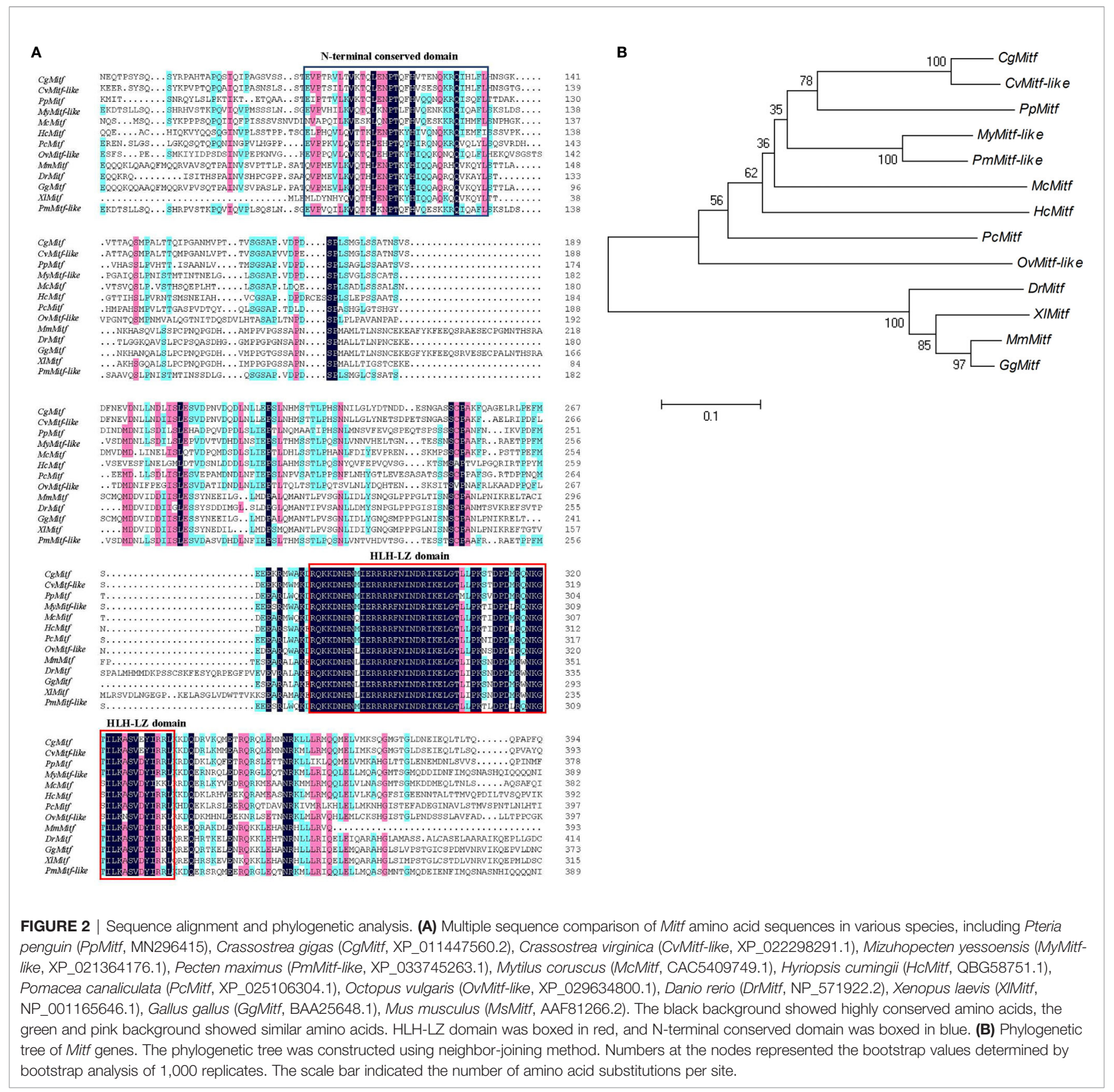

that PpMitf took part in melanin synthesis by regulating the expression of Tyr in P. penguin.

In vertebrate, PpMitf, as a central transcriptional factor, controls the differentiation, growth and survival of melanocyte via Tyr, Cdk2 (cyclin-dependent kinase 2) and Bcl2, respectively (25). So the $P p C d k 2$ and $P p B c l 2$ transcripts were analyzed after PpMitf silencing. The siRNA1 inhibited $P p C d k 2$ mRNA by 24.2\% $(P<0.05)$, and the siRNA2 inhibited $P p C d k 2$ by $40.3 \%$ $(P<0.05)$. The $P p B c l 2$ mRNA was suppressed by $31.7 \%(P<0.05)$ and $51.6 \%(P<0.01)$ by siRNA1 and siRNA2 (Figure 6). These data suggested that PpMitf was capable of regulating the expression of $C d k 2$ and $B c l 2$ in $P$. penguin, similar to that of vertebrate.

\section{Sequence Characterization of Tyr promoter}

To analyze the expression regulation of PpTyr, the upstream promoter sequence of PpTyr was amplified by standard PCR and genome walking. As shown in Figure 7, a 1,959-bp genomic sequence upstream of initiation codon (ATG) was amplified by special primers. The transcriptional start site of Tyr gene, located 16 bp upstream from the ATG, was designated as position +1 . 


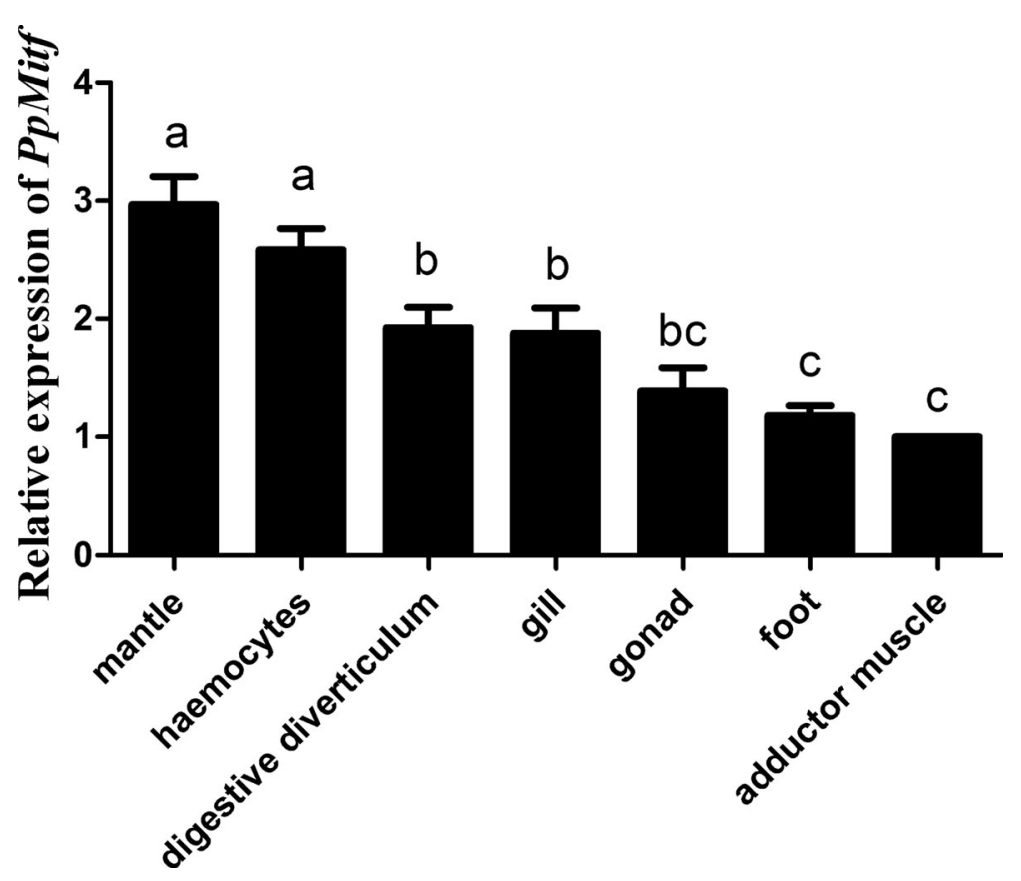

FIGURE 3 | The expression of PpMitf in different tissues was validated by qRT-PCR. The abundance of PpMitf mRNA was normalized to that of $\beta$-actin of $P$. penguin. The data were represented as mean $\pm \mathrm{SD}(N=5)$. Different letters $(\mathrm{a}, \mathrm{b}, \mathrm{bc}$ and $\mathrm{d})$ meant significant difference among these columns $(P<0.05)$.

The 1,943-bp sequence upstream of the transcriptional start site was considered as a putative promoter. Sequence analysis of the

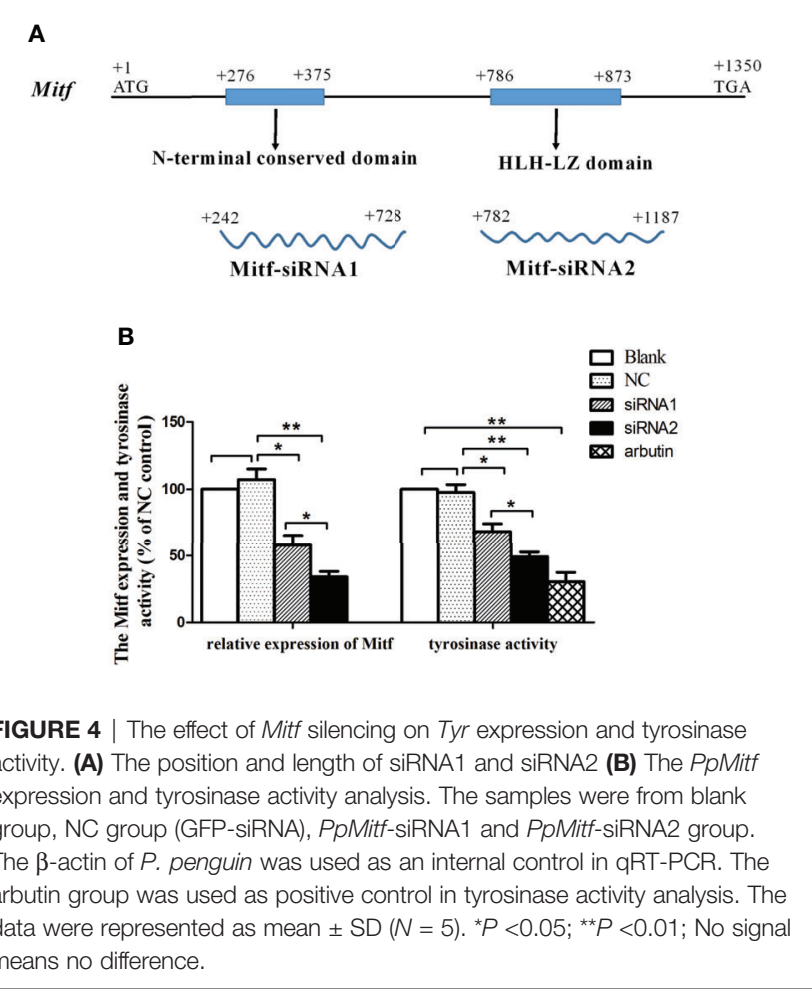

promoter revealed two typical E-box (CATGTG) elements, recognized by bHLH-LZ transcription factors, were located at positions from $-1,767$ to $-1,761$ and from $-1,613$ to $-1,607$. In addition, the tyrosinase promoter contained six putative cAMP response element (CRE) and three putative activating protein 2 (AP-2) binding sites, both of which were thought to response to intracellular Camp (26).

\section{PpMitf Activated the Expression of PpTyr}

The activity of PpTyr promoter was measured by dual-luciferase reporter assays. The Tyr-promoter-Luc (from -1,943 to -1) was constructed and transfected into the 293 T cells. The pGL3-Basic vector was transfected as control. As shown in Figure 8A, cells transfected with pGL3-Basic vector showed a low level of luciferase activity, while the Tyr-promoter-Luc construct induced a high luciferase activity, indicating that this is a strong promoter.

To investigate whether PpMitf regulated the expression of PpTyr, the 293T cells were cotransfected with Tyr-promoter-Luc plasmid and Mitf-pcDNA3.1 plasmid, or empty plasmid pcDNA 3.1 as control. The luciferase activities analysis showed that overexpression of Mitf yielded an increasing luciferase activity, being 3.02 fold of pcDNA 3.1 control cells $(P<0.05)$. The Mitf$\triangle$ HLHLZ-pcDNA3.1 plasmid was constructed and used to analyze the function of HLH-LZ domain. The overexpression of Mitf without HLH-LZ domain only yielded 23.3\% increase $(P>0.05)$ in luciferase activities compared to pcDNA 3.1 control, but yielded $63.2 \%$ decrease $(P<0.05)$ compared to MitfpcDNA3.1 group (Figures 8B, C). The data indicated that Mitf 

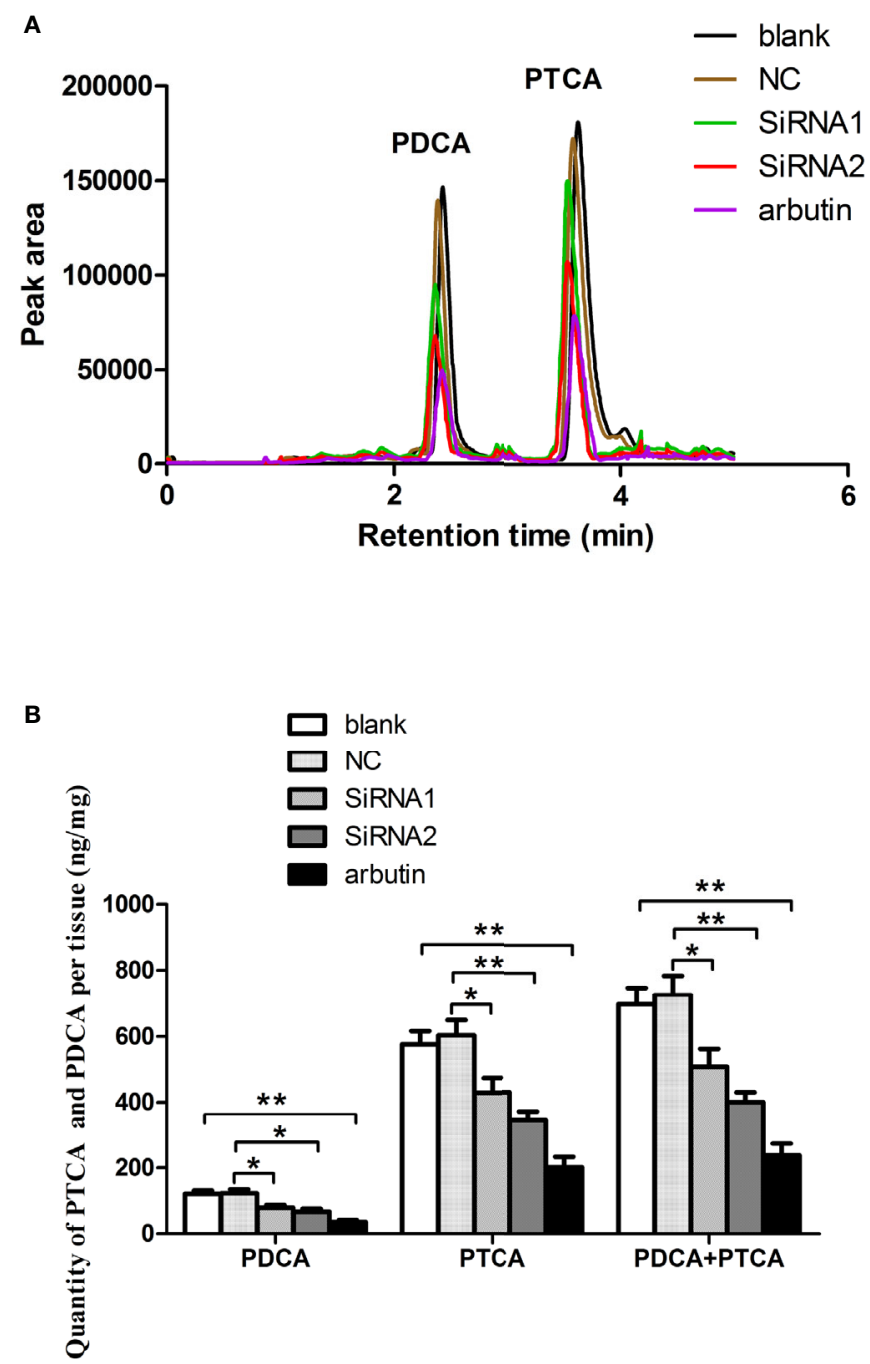

FIGURE 5 | The content of melanin from samples in blank, NC, RNAi groups and arbutin group using LC-MS/MS analysis. (A) HPLC (High Performance Liquid Chromatography) chromatograms. (B) The content of PDCA and PTCA. The data were represented as the mean \pm SD $(N=5)$. ${ }^{\star} P<0.05 ;{ }^{\star *} P<0.01$.

was able to activate the expression of Tyr, and the HLH-LZ was the key functional domain of MITF.

To elaborate the important role of E-box in Tyr promoter, the Tyr- $\triangle$ Ebox1-promoter-Luc, Tyr- $\triangle$ Ebox2-promoter-Luc and Tyr- $\triangle$ Eboxes-promoter-Luc plasmids were constructed for luciferase activity assay. The deletion from E-box1 to E-box2 yield $30.2 \%$ decrease in luciferase activity compared to Tyr promoter group $(P<0.05)$, but single E-box1 or E-box2 deletion failed to change luciferase activity (Figures 8B, C). These data indicated that the regions from $-1,767$ to $-1,607$, where two E-box domains were located, were important for Tyr promoter activity and Mitf regulation.

To confirm the successful overexpression of MITF protein in 293 cells, these transfected cells were collected for western blot detection. Because there was no endogenous expression of Mitf in 293 cells, The MITF protein level in pcDNA3.1 group was close to 0 . All cells transfected with Mitf-pcDNA3.1 plasmid had high levels of MITF protein, whose molecular weight was about $53 \mathrm{kDa}$, including the Flag-tag. Cells transfected with Mitf$\triangle$ HLHLZ-pcDNA3.1 plasmid also had a high expression level of MITF- $\triangle$ HLHLZ protein, whose molecular weight was about $47 \mathrm{kDa}$ (Figure 8C).

\section{PpMitf Silencing Inhibited Antibacterial Activity of Hemolymph Supernatant in $P$. penguin}

Since Mitf activated the expression of Tyr, which was known to play crucial roles in innate immunity of vertebrate (27), we speculated that PpMitf participated in innate immunity of $P$. penguin. After PpMitf silencing, the antimicrobial activity of hemolymph supernatant was measured and represented by its inhibition effect on E. coli growth. Because the OD600 


\section{$\square$ Blank \\ $\mathrm{NC}$ \\ שIRNA1 \\ SiRNA2}

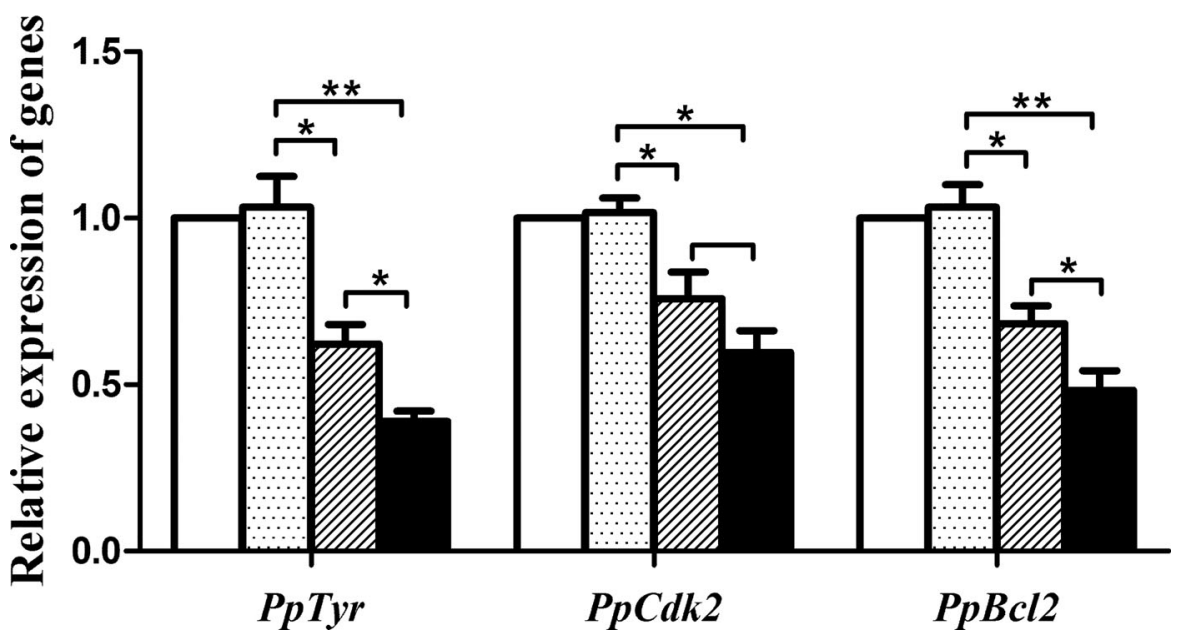

FIGURE 6 | Transcriptional levels of PpTyr, PpCdk2 and PpBc/2 after PpMitf RNAi. The qRT-PCR was performed using samples from blank, NC, siRNA1 and siRNA2 group. The abundance of mRNA was normalized to that of $\beta$-actin of $P$. penguin. The data were represented as the mean $\pm S D(N=5)$. ${ }^{\star} P<0.05 ;{ }^{\star \star} P<0.01$.

absorbance of NC group reached the maximum at $8 \mathrm{~h}, 4 \mathrm{~h}$ was defined as T50 (Figure 9A). As shown in Figure 9B, in siRNA1 group, the values of OD600 was 0.71 at $4 \mathrm{~h}$, significantly upregulated by $20.6 \%$ compared to that of NC group $(P<0.05)$, which was 0.55 . The OD600 value was 0.75 in siRNA2 group, significantly increased by $38.2 \%$ than NC group $(P<0.05)$. This indicated that the antibacterial activity of hemolymph supernatants were inhibited by Mitf silencing.

\section{The Antibacterial Activity Was Inhibited by Decreasing Melanin Content Resulted from PpMitf Silencing}

To detect whether the decrease of antibacterial activity was directly related with the melanin, we investigated the anti-bacteria effect of melanin oxidation products from $P$. penguin samples. Figures $10 A, B$ showed that the numbers of bacteria were sharply increased by $135.3 \%(P<0.01)$ and $240.7 \%(P<0.001)$ in siRNA1 and siRNA2 groups compared to the NC group. In contrast, by adding exogenetic melanin oxidation production, the number of bacteria was decreased by $84.5 \%(P<0.01)$ in NC group, $91.9 \%(P$ $<0.001)$ in siRNA1 group and $90.5 \%(P<0.001)$ in siRNA2 group. The data demonstrated melanin oxidation production from mantle of $P$. penguin had the antibacterial activity, and the decrease of melanin content resulted from $P p M i t f$ silencing was a direct reason for decline of antibacterial activity.
-1943 ACTAATGGGACTCTAGCAGGATTCGAACTCGGACATTCCCGAATCTAACACTTGGACCACAGTAAGGCTTAACTT -1868 CAGTAACATTCGTTTTTGATCACATGAAGAGTGGTATACAGGGTGTTTTTCATATATTTATTCATTATCATAAT E-box1
-1793 ACAATTATGAGCATGAATATGAaGTACATGTGTATATACATTCAAAGTTTTCATACTCTCTTGTGTTCTAGAATT -1718 TAACTTTTGTCACAAAAACGGTGGTGTTATAATCTTTTT GAAAGTTTTACTCTTCAGTAACGTTATCCAATTGTC E-box2
- 1643 CCATAAGACTTAAAGCTGTOGTAAATGTCCCATGTGTTT GTTTCTGTTTGAATTTAAGATAATCTTGTTTCCAC CRE
-1568 TAACTAACCTATGTATAAGAGGGATGGACCTATGATGTATAGCCTCATTTAATGAATTGTCATTGTCCGTGAa -1493 TCCACTCTAGCACTTTGTTGTTAGTGCCATTATCGTTGGACACCGCTTACTTTTGTATTTTACATTGTATAATTT

-1418 AaCATACGTTGAGATTTACTAAGACGGTTTCGGTCTTTGCAATCTTTGGCGGCGAGCAAGATTT CTGAAATCATC CRE

-1343 ACATAACCCGAGGTCGTCGTTAGATATCTGACACTGCATTGAGTTCAATGTTTTTTGTTTTTTTTTCGATAGAGA 1268 ATTTCATTATATACACAACTATGAAATTCCAGTCAGAGTGTGCATACCAAATATGAAGTTTATATCTCTCACAGA - 1193 TCAATAGTTGGCAAAAGACACACAAAATAAACAAACAGATATGCCAAATCCAACATGCCCCCGATCTATCTATA -1118 GAATTAATTATTATTTATCAATACACAAGTGCATTTTCGATAATTATAATGTTTGATAAAGTATAACTGTTGATT - 1043 ACTGCAACATCTCGCCATAAAACCCATATAAATACATGATTATACTGTTATTAATGCTACAGAACTCAGCTTTAC AP-2
-968 ATAAAGTCGTCOCCCTACATTAAGGCTGAGTGAAAGTTAAGTTTGAGAACATATTACATTTCTGACGAATTCCTT -968 ATAAAGTCGTCCCCCTACATTAAGGCTGAGTGAAAGTTAAGTTTGAGAACATATTACATTTCTGACGAATTCCTT
-893 AATTACTATATCATTGTCGTTTCTATACGTCTAATTCCTATTATTCTTATTTCTTAATTGCATTTATGTTGTGTT -893 AATTACTATATCATTGTCGTTTCTATACGTCTAATTCCTATTATTCTTATTTCTTAATTGCATTTATGTTGTGT
CRE
-818 GTGATGTCTAATGAGGGATAATT GTTAAATTACTAGTTATAACCATGCACATTTTTATTGAAGAGCTCAAGACA -818 GTGATGTCTAATGAGGGCATAATTGTTAAATTACTAGTTATAACCATGCACATTTTTATTGAAGAGCTCAAGACA
-743 GAATGTAATTGGGATTCCGATAACATGAACTTCTCCTCGGATAATCGAAGTAAATCTT GTCGCGCAA -743 GAATGTAAATTGTGGATTCOCGAATAACATGAACTTCTCCTCGGATAATCGAAAGTAAAATCCTGTTCGCGACAA
-668 TTATTAGAATTGAACAAAACTCGTGCAGGAAATCTTTCATACCTGCAAATATCTACGTTAATGTTTATCAAATG
AP-2 -593 GAATTGTTTAATTGGCGATCATTGTAAAACTGGCCTCTGAACATTACAACTGGCTTAAGGAAAAAATAGATTTA
-518 GATTTAGAGCAGTCGACAGCTCGAGAAAACAGTCTGAGAGTGTAAAACCATGTTGCGAATCTGTGTTTTTTACT -443 CGCOGAGACGAAAGTTCGGAGATCTATTGTCATATCCTCGGTATTGTTATCGTCATCCGTAGACAAACACGTTCA -368 CCTGAAAAATAACTTCAGAACCATTAGAGACAGGGCTTTAATATTTTCACATATTCCTTGTGCTCTCGCTTTTC 293 TTAGGTACCAATTGTTTTTTACCTTATGATTTTGAAGTTTGACCTACTTCTTGGTCATATCGTAATAACAGTAAG

-218 GGATAGGGCTTAAATATATCTTTGTGCATTCCTTGTGAAACGACCTTTCCTTACGCATCATTTTTTTTTTTGTT

-143 TGACCTTGAaGATTGACTTATTTACAAAAGGCCTTTTCTATTTAAATTTCATTCCCACCCCC

-143 TGACCTTGAAGATTGACTTATTTACAAAAGGCCTTTTCTATTTAAATTTGATT GCCACCGGCGAGTTCTGTTGTC CAAT box
TATA box +1
-68
TTCTGACAATTCTTGTTACAAATACCTATTACCGTTTCATTGGTAACATTTACTTTATTATAATATTTTCCTAT +8 TCATTACAgatg

FIGURE 7 | Sequence of the Tyr promoter. The putative transcriptional start site was indicated with box, and the initiation codon was bolded. The two conserved E-box, six CRE sites, two AP-2 sites were shaded in gray. The putative CAAT box and TATA box were underlined. 
A

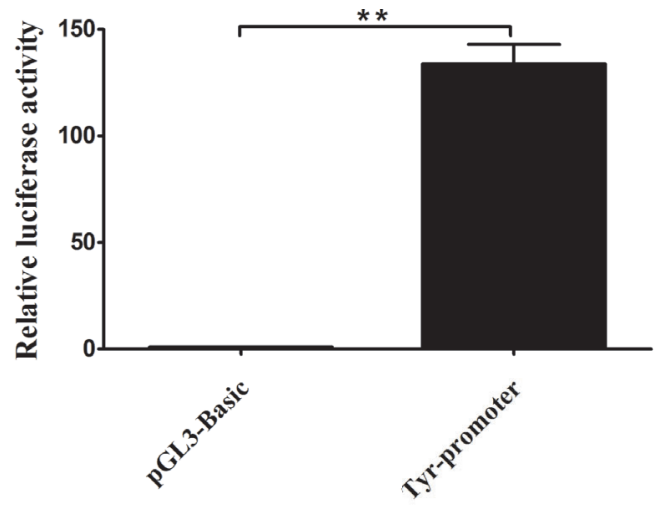

B

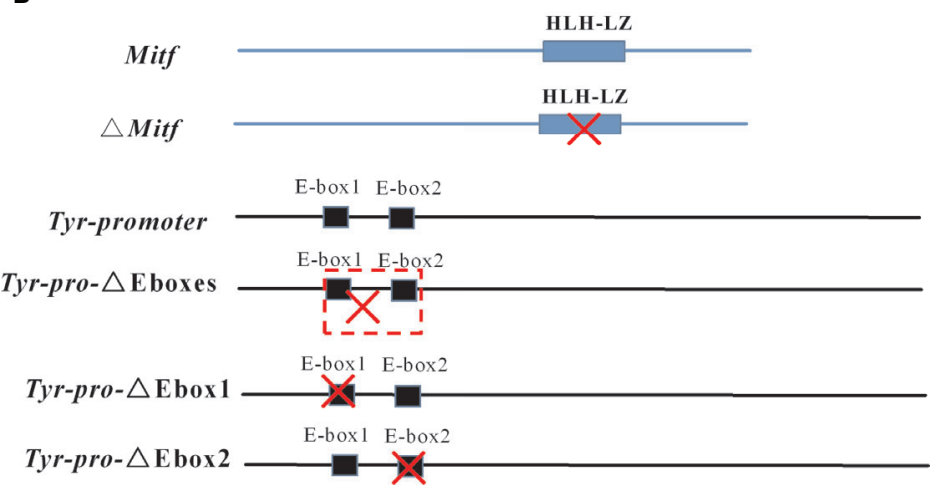

C

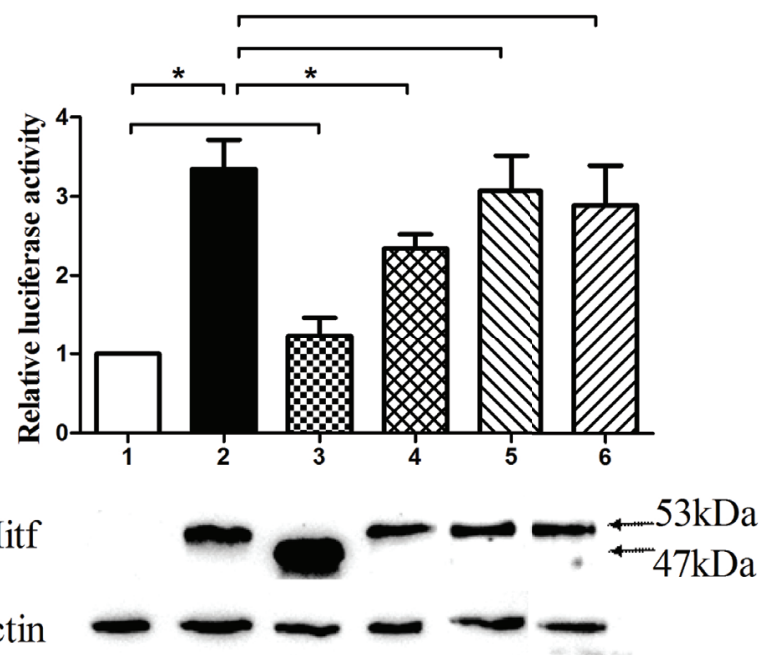

FIGURE 8 | The PpTyr promoter activity was induced by PpMitf. (A) PpTyr promoter activity analysis. The 293T cells in 24-well plates were transfected with $0.4 \mu \mathrm{g}$ of Tyr-promoter-Luc (pGL3-Basic in control) and $0.04 \mu \mathrm{g}$ pRL-cmv vector. $48 \mathrm{~h}$ post transfection, cells were collected for luciferase activity assays. (B) The construction of Mitf-pcDNA3.1, Mitf- $\triangle$ HLHLZ-pcDNA3.1, Tyr- $\triangle$ Eboxes-promoter-Luc, Tyr- $\triangle$ Ebox1-promoter-Luc and Tyr- $\triangle$ Ebox2-promoter-Luc plasmids. (C) The function analysis of HLHLZ domain in MITF and E-box in Tyr promoter by luciferase activity analysis and western blot. Column and lane 1, the 293T cells were cotransfected with pcDNA3.1 and Tyr-promoter-Luc vector; Column and lane 2, Mitf-pcDNA3.1 and Tyr-promoter-Luc; Column and lane 3, Mitf- $\triangle$ HLHLZpcDNA3.1 and Tyr-promoter-Luc; Column and lane 4, Mitf-pcDNA3.1 and $\triangle$ Eboxes-promoter-Luc; Column and lane 5, Mitf-pcDNA3.1 and $\triangle$ Ebox1-promoterLuc; Column and lane 6, Mitf-pcDNA3.1 and $\triangle$ Ebox2-promoter-Luc. The data were represented as the mean $\pm \mathrm{SD}(N=5)$. ${ }^{*} P<0.05 ;{ }^{* *} P<0.01 ;$ No signal means no difference. 
A

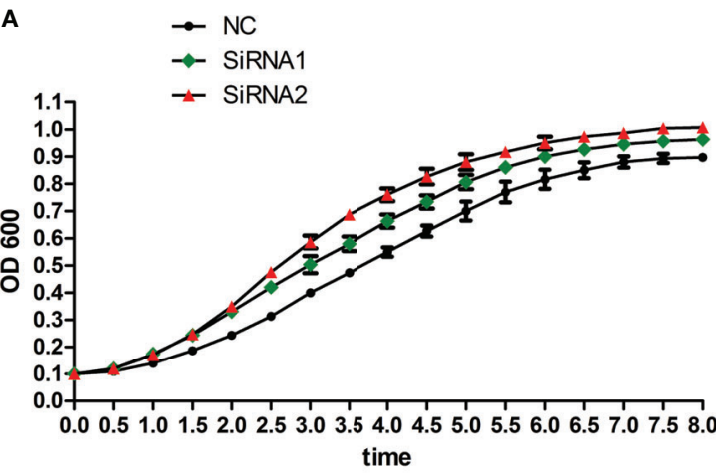

B

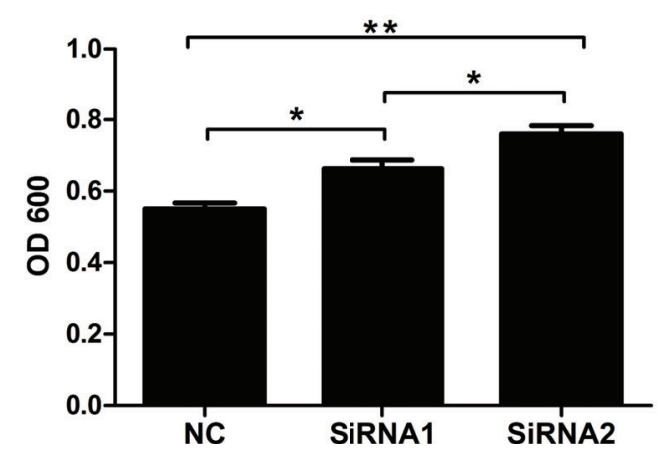

FIGURE 9 | Antibacterial activity of haemolymph supernatant from samples after PpMitf RNAi. (A) Growth curves of $E$. coli exposed to haemolymph supernatants of NC, siRNA1 and siRNA2 groups. (B) OD600 value of $E$. coli at $T 50$ in different groups. Each value was shown as mean $\pm \mathrm{SD}(N=5)$. ${ }^{*} P<0.05 ;{ }^{* *} P<0.01$.

\section{DICUSSION}

The global pearl culture industry faces two main problems, how to make the pearl colorful and how to resist the serious disease caused by pathogenic infections. The study on mechanism of color formation and immune response will be very helpful for solving the two main problems. Melanin widely exists in vertebrate and plays many role including pigmentation, anti-ultraviolet radiation and would healing (28). Therefore, we speculated melanin, which had been verified to have decisive role in color formation $(15,17)$, also participated in innate immunity in bivalves. The melanin synthesis pathway and innate immunity pathway might be interactive and interdependent, and some genes might involve in innate immune response by regulating the production of melanin.

MITF is responsible for the normal development of several cell lineages $(29,30)$. In vertebrates, MITF is a key regulator in melanin synthesis pathway, and controls the differentiation, proliferation, migration and survival of melanocytes (31-33). Meanwhile, MITF involves in immune defense by regulating a series of immunerelated genes $(7,11,12)$. In this study, a novel Mitf gene from $P$. penguin was identified, and its functions were deliberated by RNA interference. The PpMitf knockdown significantly reduced tyrosinase activity and melanin content, indicating that PpMitf participated the melanin synthesis of $P$. penguin. Meanwhile, the PpMitf knockdown also apparently decreased the antibacterial activity of hemolymph supernatant, indicating that it played a crucial role in innate immune defense of $P$. penguin. The Mitf was considered to be a bifunctional regulator in both melanin synthesis pathway and innate immunity pathway of $P$. penguin.

MITF contains a basic helix-loop-helix-leucine zipper (bHLHLZ) domain that binds DNA as dimers (34). In this research, multiple sequence alignments showed the Mitf of $P$. penguin was conserved with Mitf genes from other species, and the highest homology was found in bHLH-LZ domain as expected. Moreover, a relatively conserved region presented in the $\mathrm{N}$ terminal of PpMitf and was named as "N-terminal conserved domain". Because N-terminal conserved domain widely existed in all MiT-TFE family members, including transcription factor EB (TFEB), transcription factor EC (TFEC), transcription factor E3 (TFE3) and MITF (35), we speculated it was important for transcription factor to play the role of transcription regulation. So we respectively silenced the bHLH-LZ and N-terminal conserved domain by RNA interference to investigate their roles. Silencing of each domain apparently inhibited tyrosinase activity, melanin content, related-genes' expression and antibacterial activity, indicating both bHLH-LZ domain and Nterminal conserved domain were important for the function of Mitf gene. Furthermore, the bHLH-LZ domain silencing had more significant inhibition effect on melanin synthesis and innate immunity of $P$. penguin, which indicated bHLH-LZ domain was the key domain for Mitf gene.

Tyrosinase is a monophenol monooxygenase, which can catalyze the hydroxylation of phenols to catechols and the oxidation of catechols to quinones $(23,36,37)$, and is considered as the initial and rate-limiting enzyme for melanin production in both vertebrate $(9,10)$ and invertebrate $(38,39)$. Meanwhile, tyrosinase also is known for its role in would healing, radiation protection, primary immune responses due to its phenoloxidase activity $(40,41)$. In vertebrate, by eletromobility shift assays (EMSA), chromatin immunoprecipitation (ChIP) and reporter assays, many studies showed MITF directly regulated the expression of tyrosinase gene (42). In this study, the promoter sequence of tyrosinase was amplified and a Tyr promoter-driven luciferase reporter construct was made for luciferase activity analysis. The overexpression of Mitf significantly increased luciferase activities of Tyr-promoter, indicating that Mitf functioned by activating the expression of Tyr in P. penguin. However, the bHLH-LZ deleted MITF failed to activate the Tyr promoter, indicating that the bHLH-LZ domain was a critical functional domain of MITF protein. The results was consistent with bHLH-LZ RNA interference data, which showed a significant inhibition effect on melanin synthesis and immunity capability by bHLH-LZ domain silencing in $P$. penguin.

Moreover, two typical E-box (CATGTG) were found to locate at positions from $-1,767$ to $-1,761$ and from $-1,613$ to $-1,607$ in PpTyr-promoter. Previous studies reported that the basic region of bHLH-LZ of MITF bound to E-box (CAC/TGTG) or M-box 
A

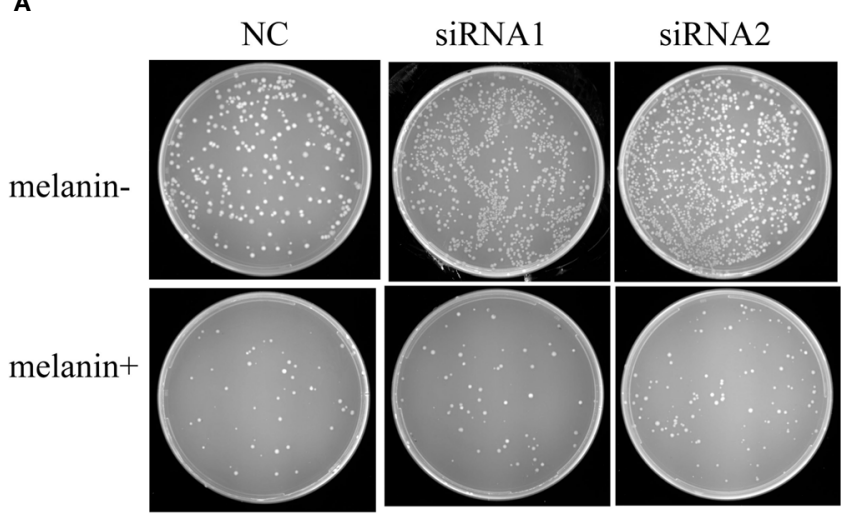

B

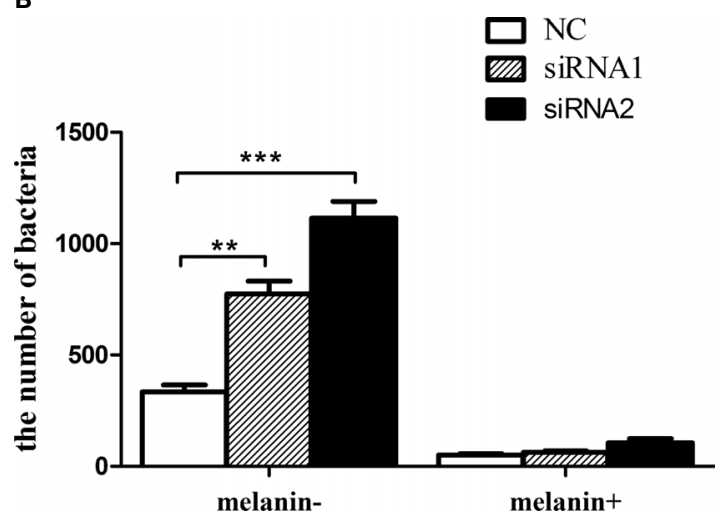

FIGURE 10 | Antibacterial activity of melanin oxidation products from P. penguin samples. (A) Photographs showed the number of E. coli after Mitf silencing and adding melanin oxidation products. (B) Histogram showed the number of $E$. coli after Mitf silencing and adding melanin oxidation products. Each value was shown as mean $\pm \mathrm{SD}\left(N=5 ;{ }^{\star} P<0.05 ;{ }^{\star \star} P<0.01\right)$.

(a core CATGTG with additional flanking residues) in the promoter of targeted genes as a homodimer or heterodimer in vertebrate (34). So the functions of E-box were analyzed in $P$. penguin. The data showed that single knockdown of E-box1 or Ebox 2 could not significantly inhibit the luciferase activity of Tyr promoter. This result was inconsistent with previous study, which reported that each of 3 E-box in tyrosinase promoter could specially bind to the MITF in mouse (43). A possible reason was that the E-box was too far from transcription start site (TSS), and weakened its role in Tyr promoter of $P$. penguin. Fortunately, both E-box deletions significantly inhibited Tyr promoter activity, indicating the critical role of region including E-box1 and E-box2. A synergistic effect was speculated to exist between E-box1 and E-box2, which enhanced the role of single E-box and strengthened the activating of Mitf to Tyr promoter (44).

Since Mitf was considered to involve in immune response by tyrosinase-mediated melanin pathway in $P$. penguin, we wondered whether melanin itself took part in immune response. In this study, the antibacterial activity of melanin oxidation products from different groups were detected. By PpMitf silencing, the melanin content was significantly decreased, and the number of bacteria was significantly increased. Oppositely, by adding melanin oxidation products, the inhibition effect on bacteria growth of different groups was apparently recovered. Our data was supported by these reports, which demonstrated that PDCA was a good antibacterial compound (45), and PTCA had antiinflammatory and anti-oxidation properties (46). The results indicated that melanin itself directly involved in innate immunity, and the Mitf-tyrosinase-melanin pathway played an important role in innate immune system of $P$. penguin.

After Mitf silencing, the expression of three downstream genes were analyzed, including Tyr, Cdk2 and Bcl2. Tyr is a key rate-limiting enzyme of melanogenesis by catalyzing three important reactions, and controls the speed of melanin synthesis (16). Cdk2 is known for its function in cell cycle, and plays an important role in controlling melanoma growth (24). $B c l 2$ is an anti-apoptotic gene, and takes part in controlling melanoma survival (47). Mitf was reported to regulate the transcriptional activity of Tyr, Cdk2 and Bcl2 by binding to their promoters in vertebrate $(16,24,45)$. Our data showed that the Mitf silencing significantly inhibited the Tyr, Cdk2 and $B c l 2$ transcripts, and suggested that Mitf might involve in melanin synthesis, melanocyte growth and melanocyte survival in P. penguin. Moreover, $C d k 2$ and $B c l 2$ themselves also play an important part in immune response. $C d k 2$ controlled peripheral immune tolerance, promoted $\mathrm{T}$ cell differentiation and restricted Treg function in immune responses (48). Bcl2 was named B cell lymphoma/leukemia-2 gene, whose mutation leaded to serious apoptosis $(49,50)$. The reduction of $C d k 2$ and $B c l 2$ transcripts after Mitf silencing in P. penguin suggested that Mitf might participate in innate immunity by regulating the expression of $B c l 2$ and $C d k 2$ genes in another immune response pathway, in addition to the melanin synthesis pathway.

In conclusion, a novel Mitf gene was characterized from $P$. penguin. The polypeptide sequence alignment showed a highly conserved bHLH-LZ domain. Tissue distribution analysis revealed that PpMitf was highly expressed in mantle and heamocytes, tissues responsible for color formation and innate immunity. PpMitf silencing significantly decreased the tyrosinase activity, melanin content, immune-related genes' expression and antibacterial activity, indicating that PpMitf involved in both melanin synthesis and innate immunity of $P$. penguin. The promoter analysis and luciferase activity analysis showed that MITF regulated melanin synthesis by activating the E-box in Tyr promoter through highly conserved bHLH-LZ domain in MITF. The antibacterial activity analysis revealed that melanin, which was regulated by Mitf, had direct antibacterial effect. The study demonstrated that PpMitf played a key role in innate immunity through activating tyrosinase-mediated melanin synthesis in $P$. penguin. Our findings have offered important insights for molecular mechanism of innate immunity in pearl shell. 


\section{DATA AVAILABILITY STATEMENT}

The datasets presented in this study can be found in online repositories. The names of the repository/repositories and accession number(s) can be found in the article/supplementary material.

\section{AUTHOR CONTRIBUTIONS}

$\mathrm{XY}$ and FY designed the experiments. FY performed experiments and wrote the manuscript. YL and BQ analyzed data. ZZ and JC contributed to the graphing. MW offered the experimental

\section{REFERENCES}

1. Amparyup P, Charoensapsri W, Tassanakajon A. Prophenoloxidase System and its Role in Shrimp Immune Responses Against Major Pathogens. Fish Shellfish Immunol (2013) 34:990-1001. doi: 10.1016/j.fsi.2012.08.019

2. Kurtz J, Franz K. Innate Defence: Evidence for Memory in Invertebrate Immunity. Nature (2003) 425:37-8. doi: 10.1038/425037a

3. Dudzic JP, Hanson MA, Iatsenko I, Kondo S, Lemaitre B. More Than Black or White: Melanization and Toll Share Regulatory Serine Proteases in Drosophila. Cell Rep (2019) 27:1050-61. doi: 10.1016/j.celrep. 2019.03.101

4. Masuda T, Otomo R, Kuyama H, Momoji K, Tonomoto M, Sakai S, et al. A Novel Type of Prophenoloxidase From the Kuruma Prawn Marsupenaeus japonicus Contributes to the Melanization of Plasma in Crustaceans. Fish Shellfish Immunol (2012) 32:61-8. doi: 10.1016/j.fsi.2011.10.020

5. Cooper D, Wuebbolt C, Heryanto C, Eleftherianos I. The Prophenoloxidase System in Drosophila Participates in the Anti-Nematode Immune Response. Mol Immunol (2019) 109:88-98. doi: 10.1016/j.molimm.2019.03.008

6. Liu YM, Ma WS, Wei YX, Xu YH. Photothermal Effect-based Cytotoxic Ability of Melanin From Mytilus Edulis Shells to Heal Wounds Infected With Drug-resistant Bacteria In Vivo. BioMed Environ Sci (2020) 33:471-83. doi: $10.3967 /$ bes 2020.052

7. Zhang SJ, Yue X, Yu JJ, Wang HX, Liu BZ. Mitf Regulates Downstream Genes in Response to Vibrio Parahaemolyticus Infection in the Clam Meretrix petechialis. Front Immunol (2019) 10:1547. doi: 10.3389/ fimmu.2019.01547

8. Perera RM, Stoykova S, Nicolay BN, Ross KN, Fitamant J, Boukhali M, et al. Transcriptional Control of Autophagy-Lysosome Function Drives Pancreatic Cancer Metabolism. Nature (2015) 524:361-65. doi: 10.1038/nature14587

9. Hofreiter M, Schoneberg T. The Genetic and Evolutionary Basis of Colour Variation in Vertebrates. Cell Mol Life Sci (2010) 67:2591-603. doi: 10.1007/ s00018-010-0333-7

10. Motyckova M, Reissmann M, Hofreiter M, Ludwig A. Colours of Domestication. Biol Rev Camb Philos Soc (2011) 86:885-99. doi: 10.1111/ j.1469-185X.2011.00177.x

11. Motyckova G, Weilbaecher KN, Horstmann M, Rieman DJ, Fisher DZ, Fisher DE. Linking Osteopetrosis and Pycnodysostosis: Regulation of Cathepsin K Expression by the Microphthalmia Transcription Factor Family. Proc Natl Acad Sci USA (2001) 98:5798-803. doi: 10.1073/pnas.091479298

12. Du J, Widlund HR, Horstmann MA, Ramaswamy S, Ross K, Huber WE, et al. Critical Role of CDK2 for Melanoma Growth Linked to its Melanocytespecific Transcriptional Regulation by MITF. Cancer Cell (2004) 6:565-76. doi: 10.1016/j.ccr.2004.10.014

13. Mao JX, Zhang XS, Zhang WJ, Tian Y, Wang XB, Hao ZL, et al. GenomeWide Identification, Characterization and Expression Analysis of the MITF Gene in Yesso Scallops (Patinopecten yessoensis) With Different Shell Colors. Gene (2019) 688:155-62. doi: 10.1016/j.gene.2018.11.096

14. Zhang SJ, Wang HX, Yu JJ, Jiang FJ, Yue X, Liu BZ. Identification of a Gene Encoding Microphthalmia-Associated Transcription Factor and its Association With Shell Color in the Clam Meretrix petechialis. Comp Biochem Phys B (2018) 225:75-83. doi: 10.1016/j.cbpb.2018.04.007 animals. XY and YL revised the manuscript. All authors contributed to the article and approved the submitted version.

\section{FUNDING}

This work was supported by National Key R\&D Program of China (2019YFD0900800), Natural Science Foundation of Guangdong Province (2021A1515011052), Guangdong Innovative and Strong School Project (230419094), and Guangdong Marine Fishery Development Foundation (B201601-Z08).

15. Yu FF, Qu BL, Lin DD, Deng YW, Huang RL, Zhong ZM. Pax3 Gene Regulated Melanin Synthesis by Tyrosinase Pathway in Pteria penguin. Int J Mol Sci (2018) 19:3700. doi: 10.3390/ijms19123700

16. Yu FF, Pan ZN, Qu BL, Yu XY, Xu KH, Deng YW, et al. Identification of a Tyrosinase Gene and its Functional Analysis in Melanin Synthesis of Pteria penguin. Gene (2018) 656:1-8. doi: 10.1016/j.gene.2018.02.060

17. Yu FF, Tang XY, Qu BL, Zhong ZM, Zhang WY, Yu XY. Kojic Acid Inhibited Melanin Synthesis by Tyrosinase Pathway in Pteria penguin. Aquac Res (2020) 51:1584-91. doi: 10.1111/are.14505

18. Szekely-Klepser G, Wade K, Wooolson D, Brown R, Fountain S, Kindt E. A Validated LC/MS/MS Method for the Quantification of pyrrole-2,3,5tricarboxylic Acid (PTCA), a Eumelanin Specific Biomarker, in Human Skin Punch Biopsies. J Chromatogr B Analyt Technol BioMed Life Sci (2005) 826:31-40. doi: 10.1016/j.jchromb.2005.08.002

19. Choi TY, Sohn KC, Kim JH, Kim SM, Kim CH, Hwang JS, et al. Impact of NAD(P)H: Quinone Oxidoreductase-1 on Pigmentation. J Investig Dermatol (2010) 130:784-92. doi: 10.1038/jid.2009.280

20. Ito S, Nakanishi Y, Valenzuela RK, Brilliant MH, Kolbe L, Wakamatsu K. Usefulness of Alkaline Hydrogen Peroxide Oxidation to Analyze Eumelanin and Pheomelanin in Various Tissue Samples: Application to Chemical Analysis of Human Hair Melanins. Pigm Cell Melanoma R (2011) 24:60513. doi: 10.1111/j.1755-148X.2011.00864.x

21. Jiang J, Zhang YB, Li S, Yu FF, Sun F, Gui JF. Expression Regulation and Functional Characterization of a Novel Interferon Inducible Gene Gig2 and its Promoter. Mol Immunol (2009) 46:3131-40. doi: 10.1016/j.molimm.2009.05.183

22. Sun ZB, Wang LL, Zhang T, Zhou Z, Jiang QF, Yi QL, et al. The Immunomodulation of Inducible Hydrogen Sulfide in Pacific Oyster Crassostrea gigas. Fish Shellfish Immunol (2014) 46:530-6. doi: 10.1016/ j.dci.2014.03.011

23. Zhou Z, Ni DJ, Wang MQ, Wang LL, Wang LL, Shi XW, et al. The Phenoloxidase Activity and Antibacterial Function of a Tyrosinase From Scallop Chlamys farreri. Fish Shellfish Immunol (2012) 33:375-81. doi: 10.1016/j.fsi.2012.05.022

24. Cheli Y, Ohanna M, Ballotti R, Bertolotto C. Fifteen-Year Quest for Microphthalmia-Associated Transcription Factor Target Genes. Pigm Cell Melanoma R (2009) 23:27-40. doi: 10.1111/j.1755-148X.2009.00653.x

25. Ferguson CA, Kidson SH. The Regulation of Tyrosinase Gene Transcription. Pigment Cell Res (1997) 10:127-38. doi: 10.1111/j.1600-0749.1997.tb00474.x

26. Maeda K, Fukuda M. Arbutin: Mechanism of its Depigmenting Action in Human Melanocyte Culture. J Pharmacol Exp Ther (1996) 276:765-9. doi: $10.1002 /$ ptr.1456

27. Andersen SO. Insect Cuticular Sclerotization: A Review. Insect Biochem Mol Biol (2010) 40:166-78. doi: 10.1016/j.ibmb.2009.10.007

28. Stappers MHT, Clark AE, Aimanianda V, Bidula S, Reid DM, Asamaphan P, et al. Recognition of DHN-melanin by a C-type Lectin Receptor is Required for Immunity to Aspergillus. Nature (2018) 555:382-6. doi: 10.1038/ nature25974

29. Zhang SJ, Yue X, Jiang FJ, Wang HX, Liu BZ. Identification of an MITF Gene and its Polymorphisms Associated With the Vibrio Resistance Trait in the Clam Meretrix petechialis. Fish Shellfish Immunol (2017) 68:466-73. doi: 10.1016/j.fsi.2017.07.035 
30. Steingrimsson E, Copeland NG, Jenkins NA. Melanocytes and the Microphthalmia Transcription Factor Network. Annu Rev Genet (2004) 38:365-411. doi: 10.1146/annurev.genet.38.072902.092717

31. Hartman ML, Czyz M. MITF in Melanoma: Mechanisms Behind its Expression and Activity. Cell Mol Life Sci (2015) 72:1249-60. doi: 10.1007/ s00018-014-1791-0

32. Cao J, Dai X, Wan L, Wang H, Zhang J, Goff PS, et al. The E3 Ligase APC/C (Cdh1) Promotes Ubiquitylation-Mediated Proteolysis of PAX3 to Suppress Melanocyte Proliferation and Melanoma Growth. Cancer (2015) 8:87. doi: 10.1126/scisignal.aab1995

33. Wang D, Zhang SJ, Liu BZ. TAF5L Functions as Transcriptional Coactivator of MITF Involved in the Immune Response of the Clam Meretrix petechialis. Fish Shellfish Immunol (2020) 98:1017-23. doi: 10.1016/j.fsi.2019.11.039

34. Goding CR, Arnheiter H. MITF-the First 25 Years. Genes Dev (2019) 33:9831007. doi: 10.1101/gad.324657.119

35. Puertollano R, Ferguson SM, Brugarolas J, Ballabio A. The Complex Relationship Between TFEB Transcription Factor Phosphorylation and Subcellular Localization. EMBO J (2018) 37:e98804. doi: 10.15252/ embj.201798804

36. Rzepka Z, Buszman E, Beberok A, Wrzesniok D. From Tyrosine to Melanin: Signaling Pathways and Factors Regulating Melanogenesis. Postepy Hig Med Dosw (2016) 70:695-708. doi: 10.5604/17322693.1208033

37. Lang D, Lu MM, Huang L, Engleka KA, Zhang M, Chu EY, et al. Pax3 Functions At a Nodal Point in Melanocyte Stem Cell Differentiation. Nature (2005) 433:884-7. doi: 10.1038/nature03292

38. Takgi R, Miyashita T. A cDNA Cloning of a Novel Alpha-Class Tyrosinase of Pinctada Fucata: Its Expression Analysis and Characterization of the Expressed Protein. Enzym Res (2014) 2014:780549. doi: 10.1155/2014/780549

39. Feng D, Li Q, Yu H, Zhao X, Kong L. Comparative Transcriptome Analysis of the Pacific Oyster Crassostrea Gigas Characterized by Shell Colors: Identification of Genetic Bases Potentially Involved in Pigmentation. PloS One (2015) 10:e0145257. doi: 10.1371/journal.pone.0145257

40. Yuan Y, Jin WL, Nazir Y, Fercher C, Blaskovich MAT, Cooper MA, et al. Tyrosinase Inhibitors as Potential Antibacterial Agents. Eur J Med Chem (2020) 187:111892. doi: 10.1016/j.ejmech.2019.111892

41. Sendoel A, Kohler I, Fellmann C, Lowe SW, Hengartner MO. HIF-1 Antagonizes p53-mediated Apoptosis Through a Secreted Neuronal Tyrosinase. Nature (2010) 465:577-83. doi: 10.1038/nature09141

42. Seberg HE, Otterloo EV, Cornell RA. Beyond MITF: Multiple Transcription Factors Directly Regulate the Cellular Phenotype in Melanocytes and
Melanoma. Pigment Cell Melanoma Res (2017) 30:454-66. doi: 10.1111/ pcmr.12611

43. Kluppel M, Beermann F, Ruppert S, Schmid E, Hummler E, Schutz G. The Mouse Tyrosinase Promoter is Sufficient for Expression in Melanocytes and in the Pigmented Epithelium of the Retina. Proc Natl Acad Sci USA (1991) 88:3777-81. doi: 10.1073/pnas.88.9.3777

44. Song J, Liu XM, Li JD, Liu HD, Peng Z, Chen HS, et al. Mechanism for Synergistic Effect of IRF4 and MITF on Tyrosinase Promoter. J Cent South Univ (2018) 43:461-8. doi: 10.11817/j.issn.1672-7347.2018.05.001

45. Beaula TJ, Packiavathi A, Manimaran D, Joe IH, Rastogi VK, Jothy VB. Quantum Chemical Computations, Vibrational Spectroscopic Analysis and Antimicrobial Studies of 2,3-Pyrazinedicarboxylic Acid. Spectrochim Acta A (2015) 138:723-35. doi: 10.1016/j.saa.2014.11.034

46. Randhawa M, Huff T, Valencia JC, Younossi Z, Chandhoke V, Hearing VJ, et al. Evidence for the Ectopic Synthesis of Melanin in Human Adipose Tissue. FASEB J (2009) 23:835-43. doi: 10.1096/fj.08-116327

47. McGill GG, Horstmann M, Widlund HR, Du J, Motyckova G, Nishimura EK, et al. Bcl2 Regulation by the Melanocyte Master Regulator Mitf Modulates Lineage Survival and Melanoma Cell Viability. Cell (2002) 109:707-18. doi: 10.1016/S0092-8674(02)00762-6

48. Xu J, Xue ZZ, Zhang C, Liu Y, Busuttil RW, Zhang JM, et al. Inhibition of Cyclin-Dependent Kinase 2 Signaling Prevents Liver Ischemia and Reperfusion Injury. Transplantation (2019) 103:724-32. doi: 10.1097/ TP.0000000000002614

49. Xia QQ, Wu XH, Rong K, Zhou ZY, Li XJ, Fei T, et al. Lysosomal Autophagy Promotes Recovery in Rats With Acute Knee Injury Through TFEB Mediation. J Orthop Surg Res (2020) 15:66. doi: 10.1096/fj.08-116327

50. Zhou XX, Wang X. Role of microRNAs in Chronic Lymphocytic Leukemia. Mol Med Rep (2013) 8:719-25. doi: 10.3892/mmr.2013.1599

Conflict of Interest: The authors declare that the research was conducted in the absence of any commercial or financial relationships that could be construed as a potential conflict of interest.

Copyright (C) $2021 \mathrm{Yu}, \mathrm{Lu}$, Zhong, Qu, Wang, Yu and Chen. This is an open-access article distributed under the terms of the Creative Commons Attribution License (CC BY). The use, distribution or reproduction in other forums is permitted, provided the original author(s) and the copyright owner(s) are credited and that the original publication in this journal is cited, in accordance with accepted academic practice. No use, distribution or reproduction is permitted which does not comply with these terms. 